\title{
An Assessment of Equity in the Brazilian Healthcare System: Redistribution of Healthcare Professionals to Address Inequities in Remote and Rural Healthcare
}

\author{
P. M. N. Akindo (Prudence M. N. Akindo)
}

Health Administration \& Human Resources,

McGurrin Hall, Scranton, PA 18510-4699

\section{E-mail address:}

akindoterence@yahoo.com

\section{Reprint address:}

Health Administration \&

Human Resources

$4^{\text {th }}$ Floor McGurrin Hall

Scranton, PA 18510-4699

Suource: Clinical Social Work and Health Intervention

Pages: $25-32$

Volume: 7

Issue: 4

\section{Reviewers:}

Dr. Johnson Nzau Mavole, Ph.D.

Catholic university of Eastern Africa, Nairobi, Kenya

e-mail: jmavole@cuea.edu

prof. MUDr. Anton Gúth, CSc.

Univerzitná nemocnica Bratislava

e-mail: anton.guth@kr.unb.sk

\section{Key words:}

Brazil's healthcare system, Healtcare professionals, Urban areas, Lucrative icentives.

\section{Publisher:}

International Society of Applied Preventive Medicine i-gap

CSWHI 2016; 7(4): 25 - 32; DOI 10.22359/cswhi_7_4_04 @ 2016 Clinical Social Work and Health Intervention

\section{Abstract:}

This document provides an in-depth assessment of Brazil's healthcare system with specific emphasis on the characteristics that shape the distribution of providers across the country. The drastic differences in the ratio of providers between the public and private sectors, alongside an even bigger distinction between available providers in rural and urban areas 
presents a hindrance to Brazil's premise of equal access to care for all. This document also presents three proven solutions that can successfully redistribute healthcare professionals (physicians in particular), in favor of Brazils remote vulnerable communities and rural regions. These proven recommendations include (1) the use of telehealth; (2) Lucrative incentives; (3) Creating and strengthening public and private partnerships.

\section{Introduction}

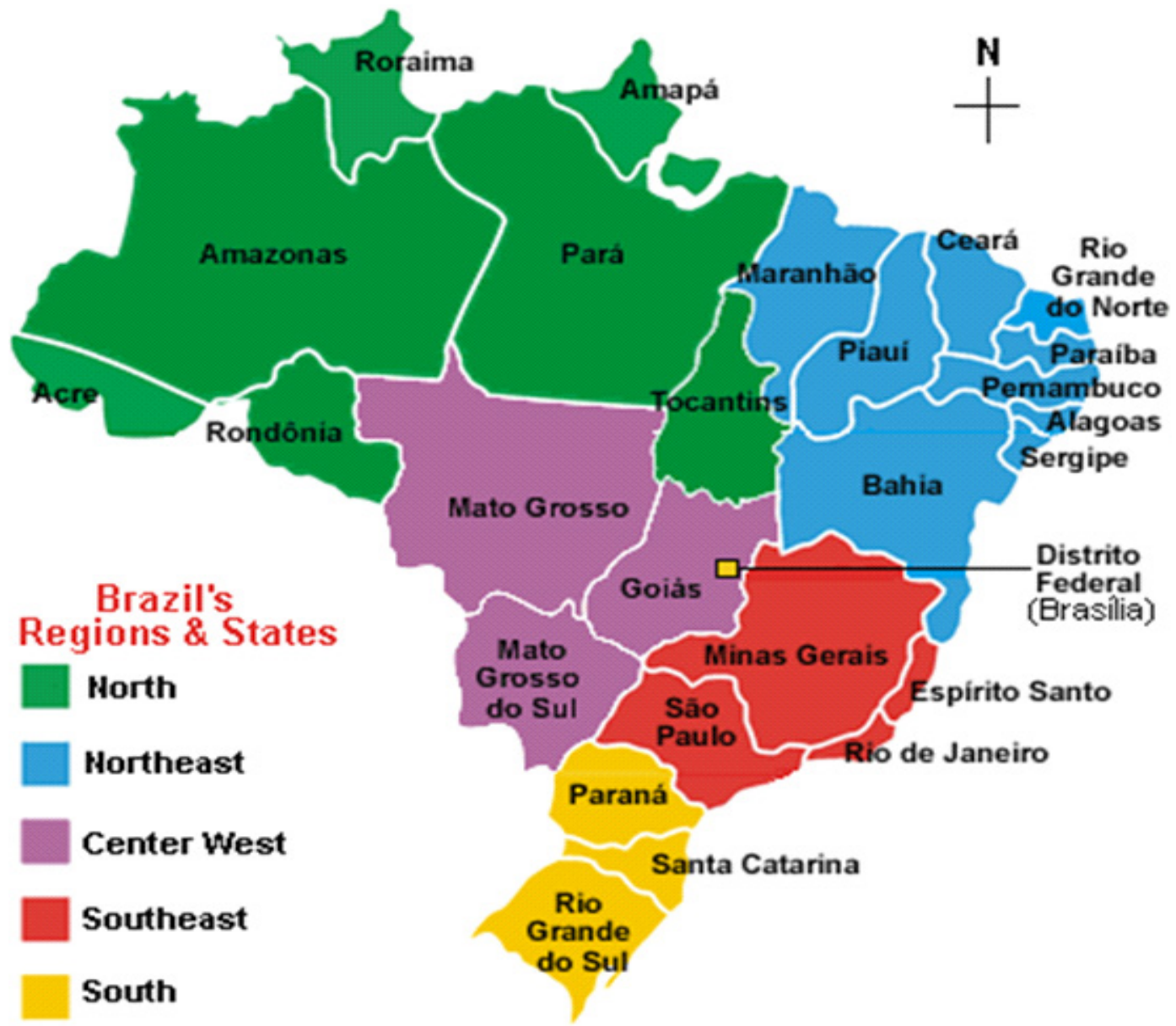

Figure 1 Geographic Regions of Brazil

Since the institution of Sistema Único de Saúde (SUS), Brazil's Universal Healthcare System, access to healthcare in Brazil has increased with utilization increases noticeable in all 26 states and demographics. Instituted under the belief that healthcare is a right and it is the duty of the government to provide it, SUS made Brazil one of the largest public healthcare providers in the world.
However, increases in healthcare utilization has consistently not been matched by sufficient healthcare spending. Between 2011 and 2015, Brazil spent 9.7 percent of it's gross domestic product (GDP) on healthcare. With a 2015 physician density "averaging 1.95 physicians per 1.000 habitants", "far below neighboring Argentina (3.2) and Uruguay (3.7)," the impact of physician shortages on 
overall quality of care cannot go unnoticed. Therefore, an increase in healthcare expenditure will help Brazil improve its allocation of federal, state and municipal resources to favor the poorest regions and segments of its population: shifting from just a focus on equal access to healthcare for all towards high quality healthcare for all.

\section{Public vs. Private Provider Distributions}

Brazil's national health system is characterized by a public and private sector. The public sector which is funded by the federal, state and municipal governments through taxes and social contributions, accounts for about 75 percent of the Brazilian population; mostly the lower-income and poor. Care in the public sector is provided free at point of delivery by public or contracted private providers. The public sector makes up about 32 percent of all Brazil hospitals and about 44 percent of all Brazilian physicians. It is evident that the provider ratio is not sufficient to handle the patient population in the public sector which is often characterized by overcrowding, long patient wait times, access difficulty etc. More so, " 46 percent of Brazil's health spending was funded by public sources in 2012, compared to an average of 72 percent in OECD countries." Therefore, inadequate governmental spending in the public sector is also a major contributor to the poor quality of care commonly associated with it.

Brazil's poor public health system is "boosting the use of private healthcare and employer-subsidized private health insurance" among 25 percent of the Brazilian population who can afford it. Responsible for about 52 percent of total healthcare spending in 2013, the private sector is the main source of health funding in Brazil's national health system. This sector makes up about 65 percent of all Brazils hospitals and about 56 percent of the physician population. With healthcare professionals choosing to work for the private system over the public due to the favorable working conditions associated with it, the significant disparities that exist between the public and private health sectors of Brazil are not surprising.

\section{Urban vs. Rural Provider Distributions}

As with most other countries in the world, the shortage of physicians in rural areas is one of the contributing factors to poor health outcomes associated with remote regions. In spite of SUS, and its push for equal access to healthcare for all Brazilians, "people living in remote and vulnerable communities still face poor access to operative health services." In 2014, 14.6 percent of the Brazilian population was considered to be living in rural areas. The north, northeast and center west regions are areas experiencing the greatest shortage of physicians. For example, in 2014, the State of Maranhão in the northeast, had 0.58 physicians per 1,000 inhabitants while the richer Rio de Janeiro had 3.44. (Figure 1. shows the geographic breakdown of Brazil by regions).

Numerous initiatives, including the recent Primary Care Professional Appreciation Program (Programa de Valorização dos Profissionais da Atenção Básica-PROVAB), have been implemented in efforts to attract health professionals to remote areas. However, these programs have not been as successful given that physician professional participation has remained below local or regional needs. In 2013, the "Mais Médicos" Program was introduced in Brazil "as part of a series of measures to fight inequalities in access to operative primary care." The Program was structured on three levels of action: the "Projeto Mais Médicos para o Brasil" (More Physicians for Brazil Project or PMMB; an emergency physician provision program for vulnerable areas. As shown in Figure 1., the success of PMMB was reliant on the successful recruitment of foreign physicians from the 49 participating countries, primarily Cuba (11,429 physicians); crediting PMMB to be 
the most effective in recruiting and placing the magnitude of physicians demanded for the remote communities. These foreign doctors "sign a three year contract", promising to dedicate their "activities to basic family medicine" in the city or town designated by the ministry "in exchange for a 10,000 BRL $(\$ 5,000)$ monthly payment." that the core of Brazil's physician shortage problem actually lies in how physicians are distributed throughout the country.

\section{Recommendations}

Rather than continue with foreign recruiting, which although effective, is only a shortterm strategy which results in high turnover;

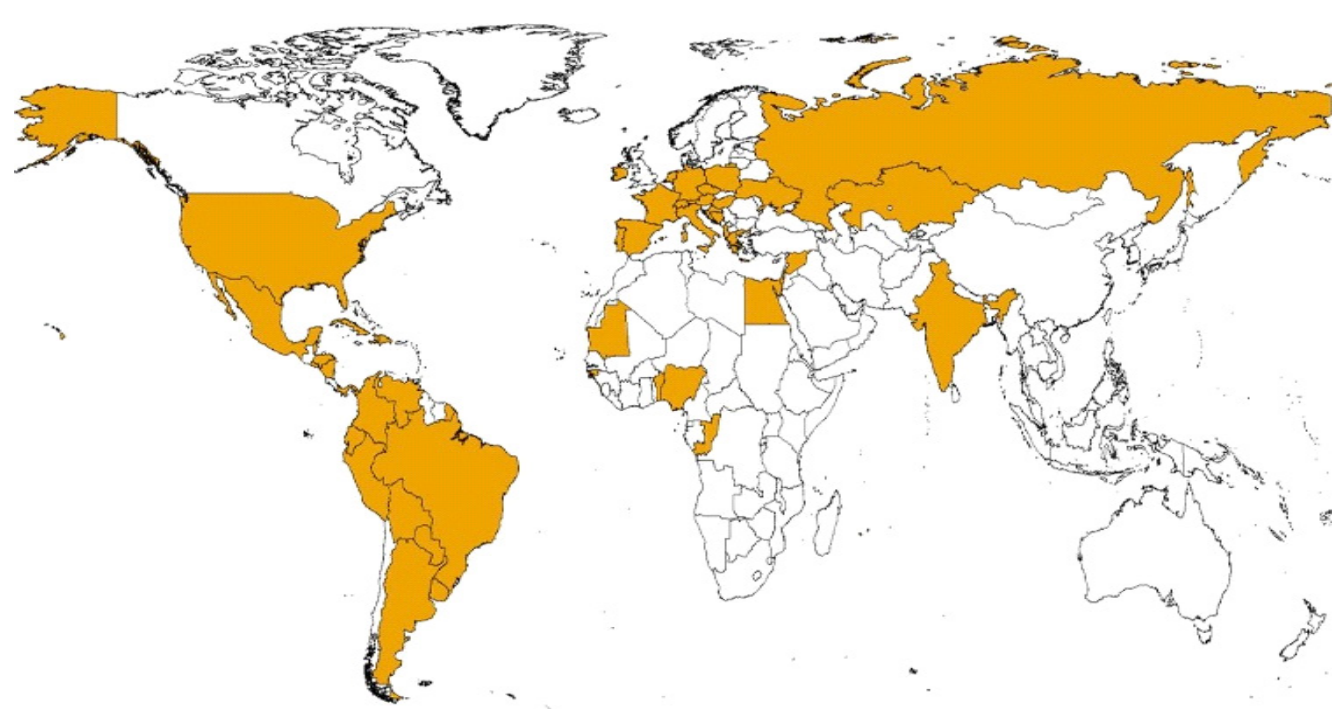

Figure 2 Countries of origin (professional practice) of the participating physicians of the Mais Médicos Para o Brasil Program.

The recruitment of foreign physicians was met with lots of opposition from most Brazilian doctors who claim "the main cause for inadequate physician coverage" is the country's "inadequate medical infrastructure." In addition, the fact that these foreign doctors are only allowed to sign three-year contracts, questions the sustainability of the PMMB program. What happens after the three years is up and the doctor decides to return back to his/her home country; does the system start all over again with recruiting and placing a new foreign physician, or does that area return to its physician-shortage condition? The problem therefore lies beyond the numbers. The federal government and medical groups must recognize sustainable strategies must be implemented in efforts to address long-term, the physician shortage problem in Brazil. Investments in telehealth, public-private partnerships, and incentives, will result in the distribution of physicians in remote vulnerable areas; reducing the existing health inequities and enhancing the quality of health in these areas.

\section{Telehealth}

"Health professionals in remote areas tend to be young and inexperienced and are often isolated and in need of further training." "The use of telehealth to provide care, impart education or conduct research," has the potential to reduce existing healthcare inequities prevalent in rural areas. By serving 
as a platform for effective "communication between primary care practitioners and specialists in reference centers," telehealth facilitates access to diagnostic tests thus enhancing healthcare quality in underserved communities. The results of pilot studies conducted on the use of telehealth in vulnerable communities of Brazil have been successful in addressing the needs of healthcare professionals in those regions. However, these studies have not been replicated or enforced as the standard of care in most of Brazil's remote vulnerable regions.

In 2005, the government of Minas Gerais State funded the establishment of The Telehealth Network, connecting the teaching hospitals of five public Universities with Municipal Health Departments. electrocardiographs, digital cameras (e.g. for photographing skin lesions), webcams and low-band-width internet." The "primary care professionals used the networks website to address questions to University staff in areas such as Medicine, Nursing, Dentistry, Physiotherapy, Nutrition, Pharmacy, Psychology and Audiology; allowing them to perform their clinical activities with the support of a network of Specialists on duty in the Universities." Monitoring for quality, and user satisfaction, in addition to using economic indicators such as implementation cost per site, unitary activity per site and patient referral cost to perform cost-effectiveness analyses; the results of the project proved effective, technically and financially feasible, and physician satisfaction in remote locations increased markedly.

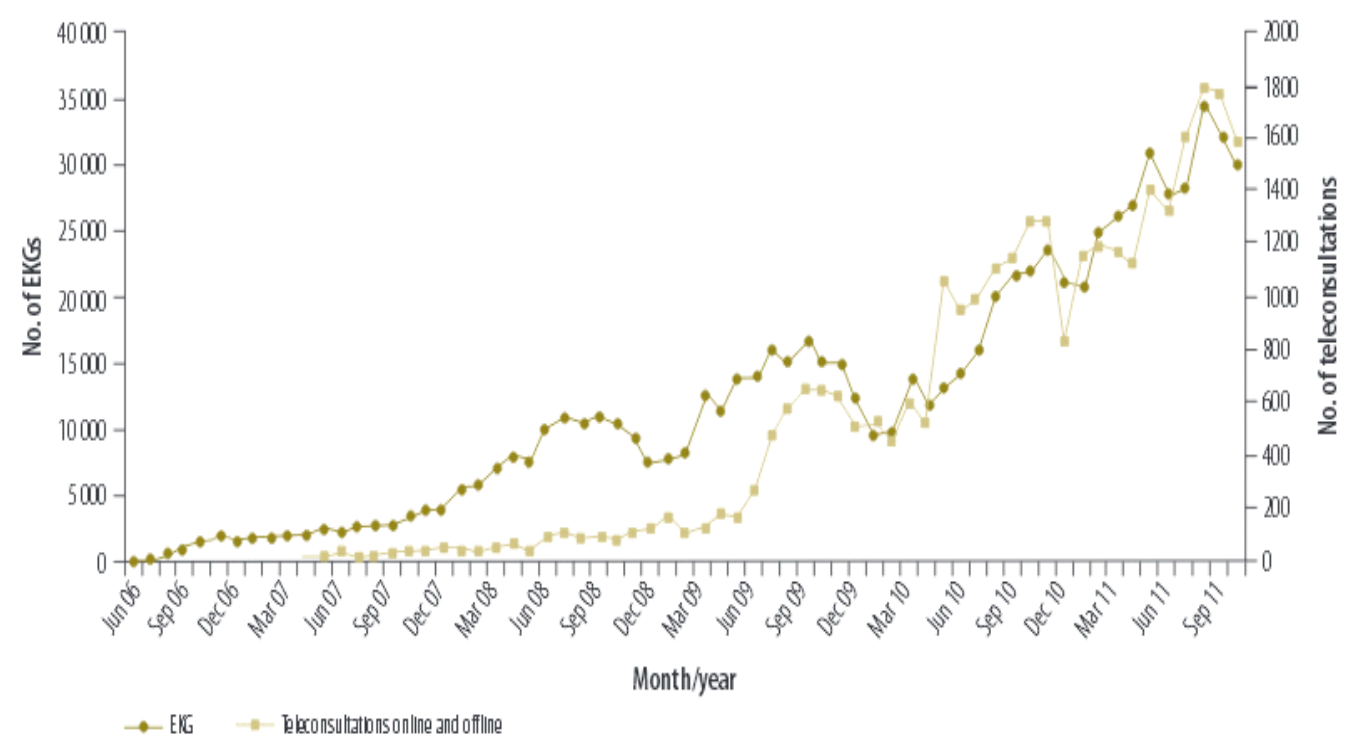

Figure 3 Electrocardiograms (EKGs) and teleconsultations conducted through the Telehealth Network of Minas Gerais, Brazil, June 2006-October 2011

In 2007, the Telehealth Network began providing teleconsultations with a focus on tele-cardiology (Minas Telecardio Project). The "network relied on low-cost technical equipment easily accessible to poor villages such as computers, printers, digital
Another pilot project, Connected Healthy Children (CHC)-Brazil, was performed in February 2014 by Cisco in partnership with the state of Sergipe Brazil. This project also resulted in significant improvements to healthcare access as well as the quality of care received 
by patients. Sergipe is located in the northeast region of Brazil, an area prone to the shortage of Medical Specialists. Limited access to collaboration technologies in Sergipe (and other rural states) is also another challenge; leaving clinicians in these rural regions "virtually unable to connect with medical peers who have the specialized expertise they need." The CHC pilot program was first launched "in collaboration with the Federal University of Sergipe" in the Sergipe municipalities of Tobais Barreto and Lagarto. The goals of the program were to; improve clinician-to-patient care; facilitate clinician-to-clinician collaboration; enhance continuing medical education; extend healthcare information and telehealth communications to the community at large. Figure 4 and 5 below show the steps taken to ensure that consultations and collaboration goals were accomplished.

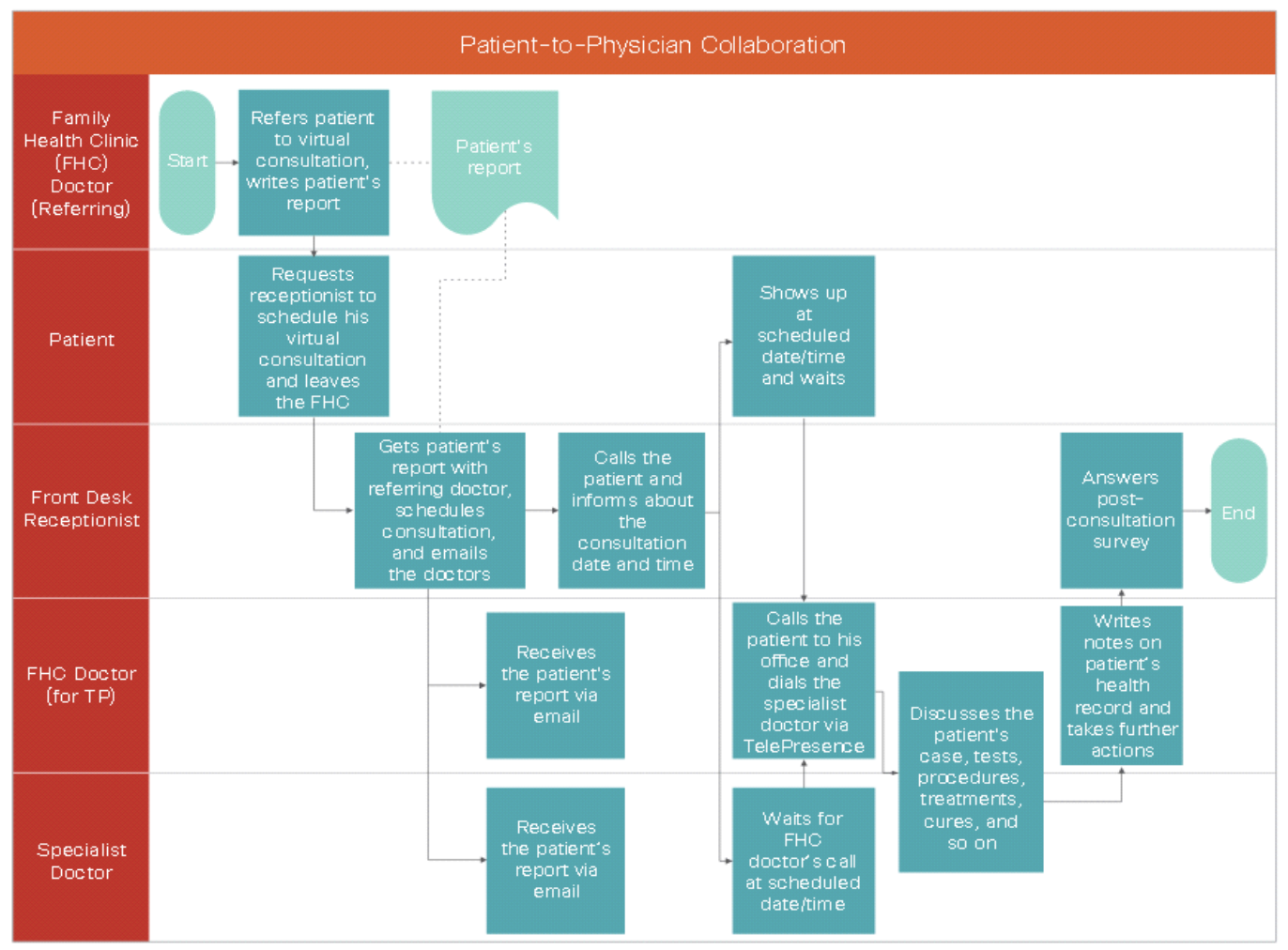

Figure 4 Steps in a Typical Consultation

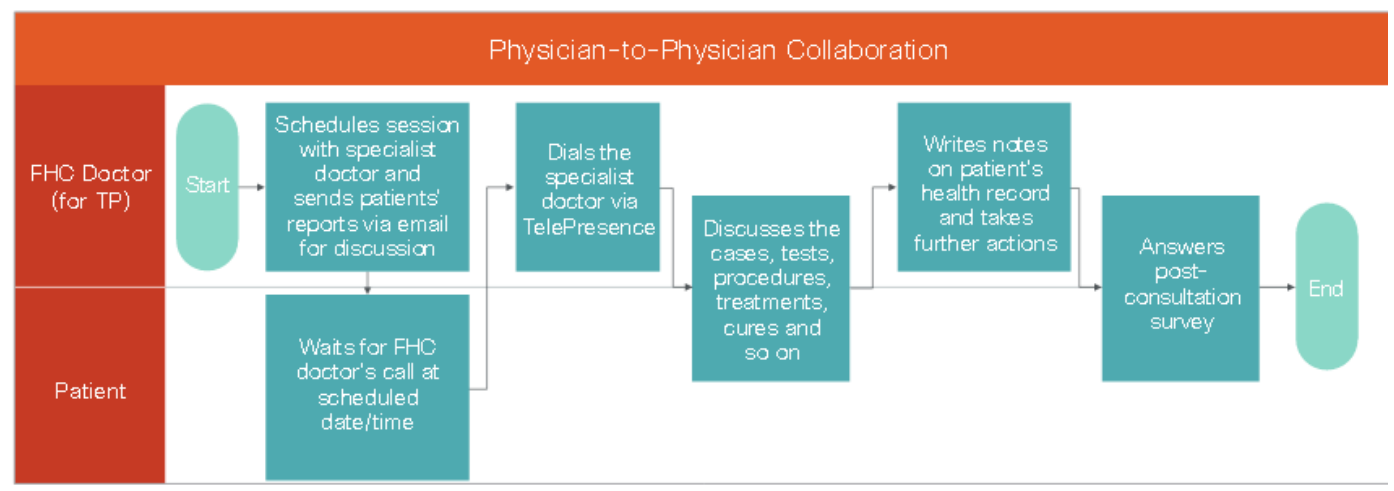

Figure 5 Physician-to-Physician Collaboration 
"Telemedicine benefits the University in the areas of research and information gathering. But its role in the community is direct and important. It can serve a large number of children and other people where face toface visits aren't possible" says Professor Angelo Antoniolli, Dean at the Federal University of Sergipe. 40 patients were able to benefit from telehealth consultations in the initial pilot of $\mathrm{CHC}$. This number included the case of... "a two-year-old boy from rural Tobias Barreto who showed symptoms of urticarial (hives), an allergic reaction that can have many causes. The boy needed to see a Specialist to confirm the diagnosis and receive a treatment plan. Instead of making a two-hour, 80 -mile $(130 \mathrm{~km})$ trip to Aracaju for an office visit, the patient's family walked with him to a local family health clinic. There, using high-definition videoconferencing, a Pediatric Allergy Specialist from UFS's Teaching Hospital conducted a real-time consultation. The doctor never had to leave the hospital, and the family avoided a stressful journey-saving travel time, travel costs, and missed work."

The effectiveness of telehealth in addressing inequities in the rural regions is evident in the number of respondents who support it $(93 \%)$. The telehealth pilot programs developed to support healthcare professionals in Minas Gerais and Sergipe, Brazil, have produced good results overall at relatively little cost. These programs are proving to be sustainable long-term strategies, helping to bridge access to care gaps between urban and rural regions in Brazil. Government investment and enforcing of telehealth as the standard of care across Brazil will promote needed replication of such models in all rural regions helping the government fulfill it's constitutional premise of equal access to high-quality care for all.

\section{Incentives}

In Brazil, "most medical students and doctors tend to come from wealthier areas which is usually where they stay." Poor urban and rural areas are usually not attractive to this elite group of professionals. Barriers hindering physician desire to practice in rural areas include but are not limited to the fact that these physicians fear professional isolation-having no one to consult on a difficult case. Therefore, to better manage the distribution of the healthcare workforce the government must provide lucrative incentives that attract physicians to rural vulnerable areas. Educational, technological and financial resources should be leveraged on by the federal government to get physicians to move shop.

Given that majority of Brazilian physicians come from wealthy communities which is where they choose to practice, providing educational incentives such as scholarships, grants, and tuition reimbursements to rural students who choose to study medicine, or to students who chose to practice in rural regions, is influential in attracting the workforce demanded in these vulnerable regions. It must also be noted that as more students from rural areas attain physician status, the probability of them returning to practice close to family is much higher than that of students from wealthy urban areas. China and Thailand (countries experiencing similar healthcare workforce distribution problems as those in Brazil) have had success in this strategy through the recruitment of rural students for free education in medical schools in exchange for hometown placement. Thailand has also instituted a mandatory requirement for clinical rotations for medical students in rural areas during medical studies; all possible strategies Brazil can emulate to attract and retain physicians in rural areas. 
Governmental investments in telehealth programs that foster collaboration between Clinicians in remote and urban areas will challenge the fear of professional isolation typically associated with rural areas. Knowing that they can virtually connect with medical peers who have the specialized expertise they need access to, serves as an incentive for more physicians to move. Of course, lucrative salaries and benefits also have the potential of incentivizing physicians to move and practice in rural areas. As stated by Francisco Eduardo de Campos (Executive Secretary of UNASUS), one of the barriers to attracting health professionals for work in rural areas is few job opportunities for their spouses. Often times, such a move leaves the physician as the sole provider for his/her household. Therefore, offering lucrative salaries/benefits for such remote locations eliminates this barrier and increases the likelihood for physicians to move and stay.

\section{Public and Private Partnerships}

Public-private partnerships (PPP) in Brazil are essential to the quality of care. Such partnerships allow for the expansion of care, improvement of facilities and increases in service efficiency. Opened in 2010, Hospital do Subúrbio, located in the underserved area of Salvador, Bahia in the northeast region, was the first PPP in Brazil. This facility was built by the public sector, but equipped, operated and managed by the private sector. "The objectives of the government of Bahia for this PPP were to ensure that all its population had access to high quality emergency health services while also establishing a new benchmark within the public health system that could be replicated throughout the country." Because payments to the private partner were linked to key performance indicators based on qualitative and quantitative targets, this PPP "created incentives for high levels of performance." Also, mitigating government risk was done through the establishment of a payment mechanism which resulted in "increasing interest by the private sector and the possibility of obtaining financing for the project." The success of the Hospital do Subúrbio's PPP has resulted in six other Brazilian states currently developing PPPs. An even more successful trend will be to see more states, especially those in rural areas replicate such PPPs so as to fulfill the premise of universal access to high quality healthcare.

\section{Conclusion}

To successfully move in the direction mandated by SUS, Brazil must redistribute its workforce to support its most vulnerable populations. Lack of skilled healthcare professionals in rural regions is a primary contributing factor to the negative health outcomes that characterize the overall health status of the country. By investing in the use of telehealth; provision of lucrative incentives; encouraging partnerships between public and private sectors; all proven strategies that have positively impacted the quality of care in certain rural regions, Brazil stands a better chance of successfully bridging that gap between access and high quality care. 